\title{
Intravitreal bevacizumab for macular edema due to branch retinal vein occlusion: 12-month results
}

This article was published in the following Dove Press journal:

Clinical Ophthalmology

2 June 2011

Number of times this article has been viewed

\section{Mehmet Demir \\ Ersin Oba \\ Gökhan Gulkilik \\ Mahmut Odabasi \\ Erhan Ozdal}

Sisli Etfal Training and Research Hospital, Eye Clinic, Sisli, Istanbul, Turkey
Correspondence: Mehmet Demir Hasta sok.No:42/6

Sisli, Istanbul, Turkey

Tel $+9021224|488|$

$\mathrm{Fax}+902122415362$

Email drmehmetfe@hotmail.com
Purpose: To present the functional and anatomic changes after intravitreal bevacizumab in eyes with macular edema (ME) due to branch retinal vein occlusion (BRVO).

Design: The study was a retrospective study.

Materials and methods: The study included 31 patients with ME due to BRVO. We compared the examination findings of patients with ME before and after intravitreal bevacizumab therapy at 12 months. The study included patients who had macular edema secondary to BRVO treated with bevacizumab. The therapy was started in the first week after occlusion. The initial therapy was three intravitreal bevacizumab injections at monthly intervals with $1.25 / 0.05 \mathrm{~mL}$ bevacizumab. Patients with a baseline visual acuity less than 0.5 (logarithm of the minimum angle of resolution [logMAR] 0.30), central macular thickness (CMT) more than $290 \mu \mathrm{m}$, and no neovascularization were included. Patients with diabetes mellitus or a history of intravitreal triamcinolone or grid laser photocoagulation therapy or ischemic BRVO were excluded. The retreatment criteria were as follows: increased CMT more than $100 \mu \mathrm{m}$ combined with a loss of visual acuity of five or more letters. The statistical analysis of this study was carried out by paired samples $t$-test (SPSS). A $P$ value of less than 0.05 was considered to be statistically significant.

Results: This retrospective study included 33 eyes of 31 patients ( 20 women, 11 men; mean age was $55.30 \pm 9.62$ years (range 36-75 years). Patients received a mean of 5.3 injections during 12 months of follow-up. The best corrected visual acuity increased from $0.66 \pm 0.20$ (logMAR) at baseline to $0.22 \pm 0.13(\operatorname{logMAR})(t=15.42 ; P<0.001)$ at month 12 . The CMT decreased from $494.15 \pm 104.16 \mu \mathrm{m}$ at baseline to $261.79 \pm 45.36 \mu \mathrm{m}$ at month $12(-232.36 \pm 109.98 \mu \mathrm{m})$; $P<0.001)$. No bevacizumab-related systemic or ocular adverse effects following intravitreal drug injections were observed. The majority of patients required reinjection(s) treatment for ME (84.9\%).

Conclusion: Intravitreal therapy using bevacizumab appears to be an effective primary treatment option for ME due to BRVO. No serious ophthalmologic or systemic side effects were observed for intravitreal bevacizumab therapy. The main disadvantage of bevacizumab therapy is the requirement of multiple injections in order to maintain visual and anatomic improvements.

Keywords: branch retinal vein occlusion, macular edema, intravitreal bevacizumab injection, central macular thickness, visual acuity

\section{Introduction}

Retinal vein occlusion (RVO) is the most common retinal vascular disease after diabetic retinopathy. Although the pathogenesis is still not fully clear, several risk factors have 
been associated with RVO, including age, diabetes mellitus, atherosclerotic retinal vessel changes, hypertension, and open-angle glaucoma. ${ }^{1-4}$

The most common sequela of branch retinal vein occlusion (BRVO) is the development of cystoid macular edema (ME) with a consecutive deterioration in vision. The major stimulus for the formation of $\mathrm{ME}$ and neovascularization in patients with RVO seems to be hypoxia-induced production of vascular endothelial growth factor (VEGF), an angiogenic factor that promotes angiogenesis and increases vascular permeability. ${ }^{5}$

The only proven treatment method for eyes with $\mathrm{ME}$ secondary to BRVO is macular grid laser photocoagulation. However, according to the Branch Vein Occlusion Study (BVOS), only patients with ME associated with BRVO and a visual acuity of 20/40 or less showed a significant visual benefit compared with the untreated control group. ${ }^{6}$

An alternative therapy for patients with ME secondary to BRVO is intravitreal anti-VEGF injection. The first report of the efficacy of intravitreal bevacizumab (a recombinant monoclonal antibbody binding to all isoforms of VEGF) in a patient with ME secondary to BRVO was in 2005. ${ }^{7}$

Several studies have evaluated the efficacy of intravitreal triamcinolone in the treatment of ME secondary to BRVO, but were only able to show stabilization or a moderate improvement in visual acuity. ${ }^{8-10}$ However, the main limitation of intravitreal triamcinolone therapy is the high rate of side effects, such as cataract formation or increased intraocular pressure. No complications or serious side effects were observed in recent studies of bevacizumab therapy. ${ }^{11-14}$

Several retrospective and prospective studies have shown the benefit of anti-VEGF treatment, with an improvement in visual acuity and a decrease of retinal thickness in patients with ME associated with RVO. ${ }^{11-13,15-22}$

We have designed a retrospective clinical study to present the effect of intravitreal bevacizumab therapy in patients with ME secondary to BRVO at 12 months.

We reviewed data of patients who had ME secondary to BRVO who were treated with bevacizumab (Avastin $1.25 \mathrm{mg} / 0.05 \mathrm{~mL}$ ) and followed up with regular visits (every month) during at least 12 months.

\section{Materials and methods}

The study included 31 patients with ME secondary to BRVO. The inclusion criteria were: ME secondary to BRVO, initial therapy started in the first week with Avastin, a baseline visual acuity below 0.5 (logarithm of the minimum angle of resolution [logMAR] 0.3), central macular thickness (CMT) more than $290 \mu \mathrm{m}$, and no neovascularization. Patients with diabetes mellitus, a history of intravitreal triamcinolone injection(s) or grid laser photocoagulation therapy, or ischemic BRVO were excluded from this study. All eyes had a complete ophthalmologic evaluation at baseline, day 1 , day 7 , month 1 , and at monthly intervals during follow-up. Examinations included best corrected visual acuity (BCVA); testing using Early Treatment Diabetic Retinopathy Study (ETDRS) charts at 4 meters in the logMAR values; slit-lamp and fundus examination, including tonometry; standardized optical cohorence tomography imaging (OCT) (Optovue, Inc Freemont, CA); and color fundus photography. Fluorescein angiography was performed at baseline and at 12 months to identify the presence of BRVO, active extravasation, and the extent of retinal nonperfusion.

All patients received three initial Avastin (bevacizumab $1.25 \mathrm{mg} / 0.05 \mathrm{~mL}$ ) injections at monthly intervals. Patients were examined monthly after three injections. The retreatment was performed when there was an increase in $1 \mathrm{~mm}$ CMT as measured by OCT macular mapping of at least $100 \mu \mathrm{m}$ with/ without a vision loss for at least five ETDRS letters.

All intravitreal injections were performed in the operating room under sterile conditions. Bevacizumab was filled and packed under sterile conditions by the institutional pharmacy, using tuberculine syringes containing a total volume $1.25 \mathrm{mg} / 0.05 \mathrm{~mL}$. Avastin was injected into vitreous body via pars plana using a $27 \mathrm{G}$ needle at inferior temporal area at $3.5 \mathrm{~mm}$ distance from limbus. The visual acuity and mean CMT are expressed as mean \pm standard deviation. The data at baseline and after injections at 12 months were evaluated statistically. The statistical analysis of this study was carried out by the paired samples $t$-test (SPSS; SPSS, Inc., Chicago, IL). A $P$ value of less than 0.05 was considered to be statistically significant.

\section{Results}

This retrospective study included 33 eyes of 31 patients (20 women, 11 men; mean age was $55.30 \pm 9.62$ years (range 36-75 years). The frequency of bevacizumab injections into vitreous body is presented in Table 1 .

The mean BCVA was $0.66 \pm 0.20$ LogMAR at baseline and improved to $0.22 \pm 0.13$ LogMAR at 12 weeks;

Table I Distribution of number of reinjections

\begin{tabular}{llc}
\hline Injections & n (eyes) & $\%$ \\
\hline 3 & 5 & 15.1 \\
$4-5$ & 13 & 39.4 \\
$6-7$ & 13 & 39.4 \\
8 & 2 & 6.1 \\
Total & 33 & 100 \\
\hline
\end{tabular}


the mean $1 \mathrm{~mm}$ CMT was $494.15 \pm 104.16 \mu \mathrm{m}$ (range 343-771).

After 12 months of follow-up, the mean logMAR values of BCVA had increased significantly to $0.66 \pm 0.20$ $(t=15.42 ; P<0.001)$, whereas mean CMT had decreased to $261.79 \pm 45.36 \mu \mathrm{m}(-232.36 \pm 109.98 \mu \mathrm{m} ; P<0.001)$ (Figure 1).
No major ophthalmologic (retinal detachment, ocular hypertension, glaucoma, uveitis, endopthalmitis, retinal artery occlusion) or systemic (thromboembolic events, systemic hypertension, myocardial infarction) side effects occurred. Neovascularization of the retina, optic disc, or iris have not been recorded.
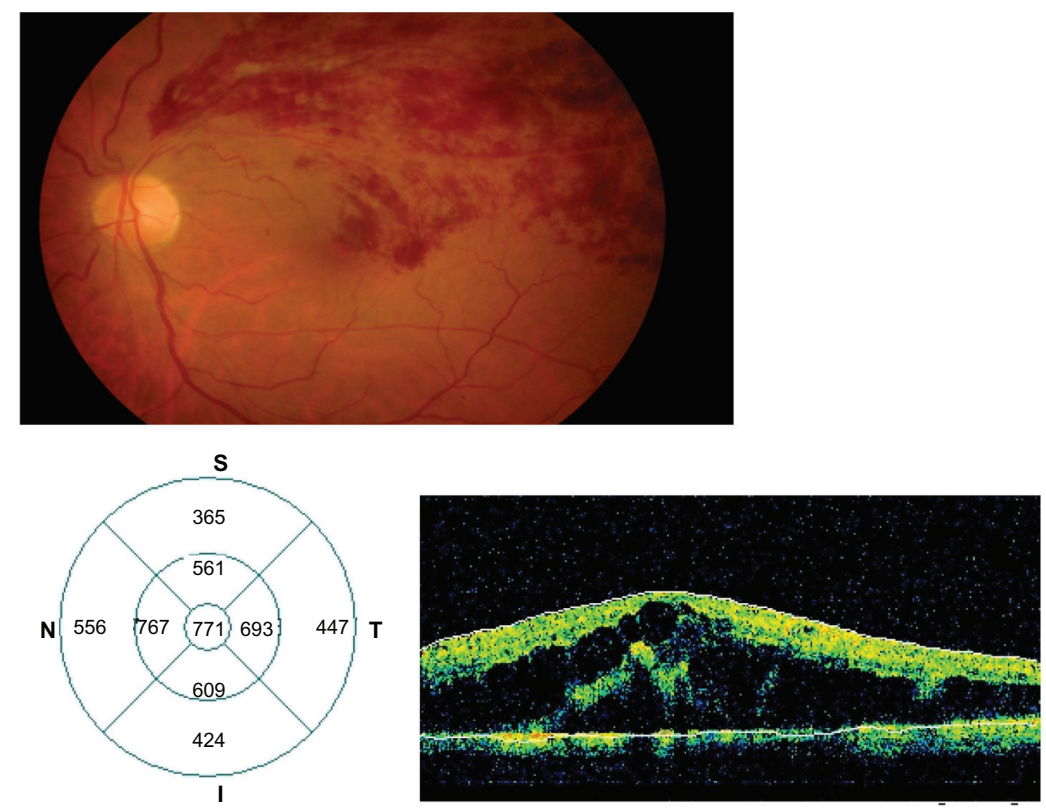

A 46- year old woman, she had left BRVO, baseline visual acuity 0.1 , CMT was $771 \mu \mathrm{m}$. Bevacizumab was started within 2 days.

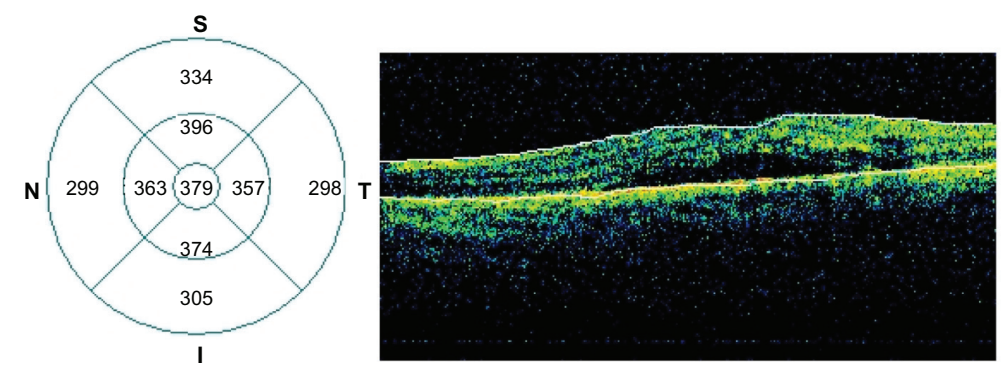

After 3 injections visual acuity was 0.3 and CMT was $379 \mu \mathrm{m}$.
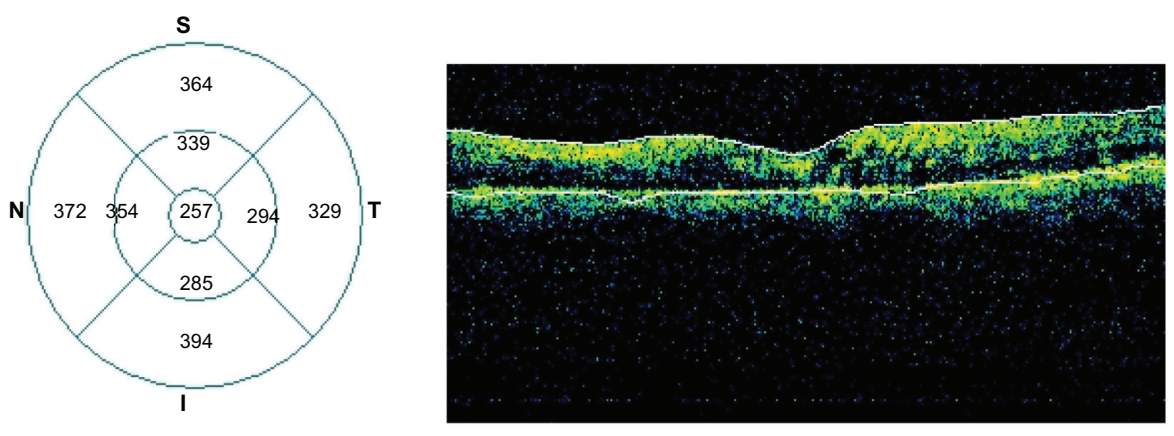

She had received 8 injections at 12 months. After 8 injections at 12 months visual acuity was 0.5 , and CMT was $257 \mu \mathrm{m}$.

Figure I The result of bevacizumab therapy in a patient with macular edema secondary to branch retinal vein occlusion (BRVO). A 46-year-old woman had left BRVO, baseline visual acuity of 0.1 , and central macular thickness (CMT) of 77I $\mu \mathrm{m}$. Bevacizumab was started within 2 days. After three injections, visual acuity was 0.3 and CMT was 379 . She had received eight injections at 12 months. After eight injections at 12 months, her visual acuity was 0.5 and CMT was $257 \mu \mathrm{m}$. 


\section{Discussion}

In this study we compared data of baseline values and after therapy with bevacizumab (injections 3-8) at 12 months. The results of this retrospective study showed that intravitreal bevacizumab treatment in patients with ME secondary to BRVO was associated with a significant improvement in visual acuity (from $0.66 \pm 0.20$ to $0.22 \pm 0.13 \log \mathrm{MAR}$ ) and with a marked decrease in CMT $(-232.36 \pm 109.98 \mu \mathrm{m} ; P<0.001)$ at 12 months.

During 12 months of follow-up, no severe ocular adverse effects, such as endophthalmitis, retinal detachment, traumatic cataract, ocular hypertension, glaucoma, uveitis, and central retinal artery occlusion, were observed.

We did not encounter any serious side effects related to bevacizumab. However, serious side effects of bevacizumab have been reported. ${ }^{15-17,23}$

A recent study showed that the results of therapy with bevacizumab were better than those with grid laser therapy in ME secondary to BRVO. ${ }^{24,25}$ However, cataract, ocular hypertension, and glaucoma are frequently encountered with triamcinolone therapy. ${ }^{26-29}$ We did not observe cataract or glaucoma in our study.

A decrease in CMT as seen by OCT and a reduction in the area of leakage with fluorescein angiography were observed. Avascular areas were stable and they did not progress after treatment with Avastin.

Although nearly all patients showed an important response to intravitreal Avastin treatment with an increase in visual acuity and a reduction in CMT initial therapy, the ME had not resolved completely in $84.9 \%$ of all patients after three injections. The majority of patients required retreatment for ME.

The main disadvantage of Avastin is short duration of the therapeutic effect and the requirement of reinjections. ${ }^{11,19,21,22}$ We did not measure anti-VEGF levels, but some studies also showed a close correlation between aqueous VEGF levels and the severity of ME in patients with RVO. ${ }^{30,31}$

Finally, intravitreal bevacizumab therapy appears to be an effective and safe treatment option for ME secondary to BRVO. The main disadvantage is the requirement for multiple injections in order to maintain good visual acuity and macular thickness.

\section{Disclosure}

The authors involved in this study have no proprietary or material conflicts of interest to declare in relation to this work.

\section{References}

1. Cugati S, Wang JJ, Rochtchine E, Mitchell P. Ten-year incidence of retinal vein occlusion in an older population: the Blue Mountain Eye study. Arch Ophthalmol. 2006;124:726-732.
2. Hayreh SS, Zimmerman B, Mc Carthy MJ, Podhajsky P. Systemic diseases associated with various types of retinal occlusion. Am J Ophthalmol. 2001;131:61-77.

3. Blond J, Glacet-Bernard A, Bayani N, et al. Retinal vein occlusion and hyperhomocysteinemia. J Fr Opthalmol. 2003;26:249-253.

4. Rath EZ, Frank RN, Shin DH, Kim C. Risk factors for retinal vein occlusion. A case-control study. Ophthalmology. 1992;99:509-514.

5. Aiello LP, Avery RL, Arrig PG, et al. Vascular endothelial growth factor in ocular fluid of patients with diabetic retinopathy and other retinal disorders. N Engl J Med. 1994;331:1480-1487.

6. Branch Retinal Vein Occlusion Study Group. Argon laser photocoagulation for macular edema in branch vein occlusion. Am J Ophthalmol. 1984;98:271-282.

7. Rosenfeld PJ, Fung AE, Puliafito CA. Optical cohorence tomography findings after an intravitreal injection of bevacizumab (Avastin) for macular edema from central vein occlusion. Ophthalmic Surg Lasers Imaging. 2005;36:336-339.

8. Avitabile T, Longo A, Reibaldi A. Intravitreal triamcinolone compared with macular grid photocoagulation for the treatment of cystoid macular edema. Am J Ophthalmol. 2005;140:695-702.

9. Karacorlu M, Karacorlu SA, Ozdemir H, et al. Intravitreal triamcinolone acetonide for treatment of serous macular detachment in central vein occlusion. Retina. 2007;27:1026-1030.

10. Gregori NZ, Rosenfeld PJ, Puliafito CA, et al. One-year safety and efficacy of intravitreal triamcinolone acetonide for the managment of macular edema secondary to central vein occlusion. Retina. 2006;26: 889-895.

11. Prager F, Michels S, Kriechbaum K, et al. Intravitreal bevacizumab (Avastin) for macular oedema secondary to retinal vein occlusion: 12-month results of prospective clinical trial. Br J Ophthalmol. 2009; 93:452-456.

12. Ahmadi AA, Chuo JY, Banashkevich A, et al. The effects of intravitreal bevacizumab on patients with macular edema secondary to branch retinal vein occlusion. Can J Ophthalmol. 2009;44:154-159.

13. Kim JY, Park SP. Comparison between intravitreal bevacizumab and triamcinolone for macular edema secondary to branch retinal vein occlusion. Korean J Ophthalmol. 2009;23:259-265.

14. Hou J, Tao Y, Jiang YR, et al. Intravitreal bevacizumab versus triamcinolone acetonide for macular edema due to branch retinal vein occlusion: a matched study. Chin Med J (Eng). 2009;122:2695-2699.

15. Iturradle CB, Spaide RF, Meyerle CB, et al. Intravitreal bevacizumab (Avastin) treatment of macular edema in central retinal vein occlusion: a short-term study. Retina. 2006;26:279-284.

16. Hsu J, Kaiser RS, Sivalingam A, et al. Intravitreal bevacizuma (Avastin) in central vein occlusion. Retina. 2007;27:1013-1019.

17. Rabena MD, Pieramici DJ, Castellarin AA, et al. Intravitreal bevacizumab (Avastin) in the treatment of macular edema secondary to branch retinal vein occlusion. Retina. 2007;27:419-425.

18. Abegg M, Tappeiner C, Wolf-Schnurrbush U, et al. Treatment of branch retinal vein occlusion induced macular edema with bevacizumab. $B M C$ Ophthalmol. 2008;8:18.

19. Figueroa MS, Contreras I, Noval S, Arruabarrena C. Results of bevacizumab as the primary treatment for retinal vein occlusions. Br J Ophthalmol. 2010;94:1052-1056.

20. Guthoff R, Meigen T, Hennemann K, Schrader W. Comparison of bevacizumab and triamcinolone for treatment of macular edema secondary to branch retinal vein occlusion in pair-matched analysis. Ophthalmologica. 2010;224:319-324.

21. Wu L, Arevalo JF, Berrocai MH, et al. Comparison of two doses intravitreal bevacizumab as primary treatment for macular edema secondary to branch retinal vein occlusions: results of the Pan American Collaborative Retina Study Group at 24 months. Retina. 2009;29: 1396-1403.

22. Ach T, Hoeh AE, Schaal KB, et al. Long-term follow-up of OCT-guided bevacizumab treatment of macular edema due to retinal vein occlusion. Graefes Arch Clin Exp Ophthalmol. 2009;247:1635-1641. 
23. Fung AE, Rosenfeld PJ, Reichel E. The International Intravitreal Bevacizumab Safety Survey: using the internet to assess drug safety worldwide. Br J Ophthalmol. 2006;90:1344-1349.

24. Russo V, Barone A, Conte E, et al. Bevacizumab compared with macular laser grid photocoagulation for cystiod macular edema in branch retinal vein occlusion. Retina. 2010;30:1324-1325.

25. Cekic O, Cakır M, Yazıcı AT, et al. A comparison of three different intravitreal treatment modalities of macular edema due to branch retinal vein occlusion. Curr Eye Res. 2010;35:925-929.

26. Rezende MP, Dias AF, Oshima A, et al. Study of visual acuity and intraocular pressure in the treatment of macular diabetic edema with intravitreous triamcinolone. Arq Bras Oftalmol. 2010;73:129-134.

27. Vasconcelos-Santos DV, Nehemy PG, Schachat AP, Nehemy MB. Secondary ocular hypertension after intravitreal injection of $4 \mathrm{mg}$ of triamcinolone acetonide: incidence and risk factors. Retina. 2008;28:573-580.
28. Gillies MC, Islam FM, Larsson J, et al. Triamcinolone-induced cataract in eyes with diabetic macular oedema: 3-year prospective date from a randomised clinical trial. Clin Experiment Ophthalmol. 2010;38: 605-612.

29. Islam MS, Vernon SA, Negi A. Intravitreal triamcinolone will cause posterior subcapsular cataract in most eyes with diabetic maculopathy within 2 years. Eye (Lond). 2007;21:321-323.

30. Noma H, Funatsu H, Yamasaki, et al. Aqueous humour of cytocines are correlated to vitreous levels and severity of macular oedema in branch retinal vein occlusion. Eye (Lond). 2008;22:42-48.

31. Noma H, Minamoto A, Funatsu H, et al. Intravitreal levels of vascular endothelial growth factor and interleukin-6 are correlated with macular edema in branch retinal vein occlusion. Graefes Arch Exp Ophthalmol. 2006;244:309-315.
Clinical Ophthalmology

\section{Publish your work in this journal}

Clinical Ophthalmology is an international, peer-reviewed journal covering all subspecialties within ophthalmology. Key topics include: Optometry; Visual science; Pharmacology and drug therapy in eye diseases; Basic Sciences; Primary and Secondary eye care; Patient Safety and Quality of Care Improvements. This journal is indexed on

Submit your manuscript here: http://www.dovepress.com/clinical-ophthalmology-journal

\section{Dovepress}

PubMed Central and CAS, and is the official journal of The Society of Clinical Ophthalmology (SCO). The manuscript management system is completely online and includes a very quick and fair peer-review system, which is all easy to use. Visit http://www.dovepress.com/ testimonials.php to read real quotes from published authors. 